\title{
Effect of heparin administration to sheep on the release profiles of circulating activin $\mathrm{A}$ and follistatin
}

\author{
Kristian L Jones, David M de Kretser and David J Phillips \\ Centre for Molecular Reproduction and Endocrinology, Monash Institute of Reproduction and Development, Monash University, Clayton, Victoria 3168, \\ Australia \\ (Requests for offprints should be addressed to D Phillips; Email: david.phillips@med.monash.edu.au)
}

\begin{abstract}
Activin A and follistatin are normally present in relatively low amounts in the circulation. Heparin administration elicits a rapid and robust release of these proteins, although this phenomenon is poorly defined. In the present studies, the response to heparin administration was evaluated in the plasma of adult ewes in terms of whether it was dose-dependent, could be neutralized, was responsive to multiple stimulation, and the nature of the activin $\mathrm{A}$ and follistatin released. Activin A and follistatin were rapidly released by heparin in a dose-dependent manner $(25,100$ or $250 \mathrm{IU} / \mathrm{kg}$ ), with differences in the response as adjudged by peak concentration, timing of the peak and area under the curve. The heparin response could be blocked by pretreatment with protamine; conversely protamine injection alone $(2 \mathrm{mg} / \mathrm{kg})$ elicited release of
\end{abstract}

follistatin but not activin A. Repeat administration of heparin at three-hourly intervals resulted in activin and follistatin responses to each injection, but each subsequent stimulation increased and extended the responses, consistent with saturation of the heparin clearance mechanism. Size exclusion chromatography of plasma samples confirmed that the majority of activin and follistatin released by heparin was a complex, whereas follistatin released by protamine was unbound. These data are consistent with a large pool of activin A and follistatin resident on extracellular matrices, with the rapid response implicating the vascular endothelium as the prime site of release following administration of these commonly used anticoagulant therapies.

Journal of Endocrinology (2004) 181, 307-314

\section{Introduction}

Activin $A$, a member of the transforming growth factor- $\beta$ superfamily, consists of inhibin $\beta_{\mathrm{A}}$ subunits formed into a dimer linked by disulphide bonds. Other activins are formed by dimerization of the $\beta$ subunits, including activin $\mathrm{B}\left(\beta_{\mathrm{B}}-\beta_{\mathrm{B}}\right)$ and activin $\mathrm{AB}\left(\beta_{\mathrm{A}}-\beta_{\mathrm{B}}\right)$, whilst inhibin itself consists of a dimer of the inhibin $\alpha$-subunit and a $\beta$-subunit (Ling et al. 1986b). Activin A was first identified as an enhancer of pituitary follicle-stimulating hormone (FSH) release (Ling et al. 1986a,b, Vale et al. 1986) although subsequently, and consistent with its widespread expression, it is also involved in the regulation of erythropoiesis (Yu et al. 1989), mesoderm induction and bone morphogenesis (Mather et al. 1997). Recent investigations from our group and others have also implicated activin A as a cytokine and growth factor relevant to inflammatory diseases, wound healing, fibrosis and cardiovascular disease (Hübner et al. 1996, Jones et al. 2000, Phillips et al. 2001, Engelse et al. 2002).

Follistatin, first isolated due to its capacity to suppress FSH secretion by cultured pituitary cells (Esch et al. 1987, Robertson et al. 1987, Ueno et al. 1987), is a glycosylated, single-chain binding protein capable of neutralizing activin activities (Nakamura et al. 1990). The gene structure of follistatin revealed two precursors, a follistatin-344 form and a carboxyl terminal-truncated follistatin-317 form, which are generated via alternate splicing. These two transcripts produce follistatin-315 and follistatin-288 respectively, after the cleavage of the signal peptide (Sugino et al. 1993). The isoforms have different binding affinities for activin, with the $K_{\mathrm{d}}$ of follistatin-288 and follistatin-315 for activin estimated to be 46.5 and $432 \mathrm{pM}$ respectively (Hashimoto et al. 2000). These isoforms also display different affinities for cell surfaces, with the truncated follistatin-288 isoform having a greater affinity, specifically for heparan sulphate proteoglycans (HSPG) (Sugino et al. 1993). Peptide and antibody mapping approaches have elucidated that follistatin contains a heparin binding site at residues 74-86 (Inouye et al. 1992, Sumitomo et al. 1995).

Many growth factors containing heparin binding sites have been documented as being released into the circulation by heparin analogues (Bobik \& Campbell 1993). Consistent with the above biochemical analyses, a study in ewes showed that administration of unfractionated porcine 
heparin caused an acute elevation in plasma concentrations of follistatin (Klein et al. 1996). This is most likely to occur from follistatin bound to HSPG associated with cell surfaces (Sugino et al. 1993, Klein et al. 1996, Hashimoto et al. 1997). Whether activin is also released by heparin was not investigated by Klein and colleagues and the activin structure does not contain a classical heparin binding motif or demonstrate any affinity for cell surfaces without the presence of follistatin (Yamane et al. 1998). Nevertheless, a subsequent study in patients undergoing cardiovascular surgical procedures showed that both activin A and follistatin concentrations increased immediately following the point in the surgical procedure where 5000 IU heparin were administered (Phillips et al. 2000). An analysis of the kinetics of the response in patients receiving heparin during coronary angiography procedures suggested that the majority of the activin and follistatin was released as a complex, but the disappearance curves and half-life kinetics for activin and follistatin differed (Phillips et al. 2000). The latter raised the possibility that the manner in which activin and follistatin are released, and potentially reassociate with cell surfaces, has multiple components. The current studies were initiated to explore these responses in more detail. Specifically, the aims were to define if the release of activin and follistatin by heparin (i) was dose-dependent, (ii) could be blocked by the use of the heparin blocking agent, protamine, (iii) was altered by repeated doses of heparin, i.e. was saturable, and (iv) was largely composed of activin complexed to follistatin.

\section{Materials and Methods}

\section{Animals and general details}

All experiments were conducted in accordance with the National Health and Medical Research Council (NHMRC) Australian Code of Practice for the Care of Animals for Scientific Purposes (1997) and were approved by the Victorian Institute of Animal Sciences Animal Ethics Committee. Adult Corriedale ewes (separate animals for each experiment) were weighed (median weight $53 \mathrm{~kg}$, range $44-61.5 \mathrm{~kg}$ ), randomly allocated into groups of four animals, and housed indoors in individual pens with access to a maintenance ration of lucerne chaff with tap water available ad libitum. The day before intensive blood sampling, indwelling catheters (Dwellcath, Tuta Laboratories, Lane Cove, Australia) were inserted into the external jugular vein under local anaesthesia. A bleeding line (Manometer tubing, Tuta Laboratories) with a 3-way tap was attached to allow blood sampling. Throughout the studies, the patency of the catheters was maintained with $0.9 \%$ saline solution containing $37 \mathrm{mM}$ dipotassium ethylenediaminetetra-acetic acid (EDTA, BDH Laboratory Supplies, Poole, Dorset, UK), which does not affect circulating concentrations of activin A or follistatin (Klein et al. 1996). Blood samples (5 ml) were immediately spun at $250 \mathrm{~g}$ at $4{ }^{\circ} \mathrm{C}$ in blood collection tubes containing EDTA $(50 \mu \mathrm{l}$ of $740 \mathrm{mM}$ EDTA solution per tube). Plasma from each sample was stored at $-20^{\circ} \mathrm{C}$ until assayed.

\section{Experimental details}

In a first experiment, groups of four animals received an intravenous bolus injection of $0,25,100$ or $250 \mathrm{U} / \mathrm{kg}$ bodyweight unfractionated porcine heparin (David Bull Laboratories, Mulgrave, Victoria, Australia) in $0.9 \%$ sterile saline solution. These doses were chosen to bracket the dose of heparin (5000 IU, Williams et al. 1989) used commonly in human cardiovascular procedures (assuming an average ewe bodyweight of $50 \mathrm{~kg}$ ). The injection of heparin was administered via the bleeding line and was immediately followed by a flush of 10-15 ml EDTAsaline. Blood samples were collected at $-5,0,5,10,15$, $25,40,60,120,180,240,300$ and $360 \mathrm{~min}$ relative to the heparin injection. Plasma samples were subsequently assayed for activin A and follistatin concentrations.

The effect of neutralizing heparin with protamine on the activin and follistatin response was examined in groups of four ewes receiving an intravenous injection of one of the following: $0.9 \%$ sterile saline, $100 \mathrm{U} / \mathrm{kg}$ heparin, a premixed solution of $100 \mathrm{U} / \mathrm{kg}$ heparin and $2 \mathrm{mg} / \mathrm{kg}$ protamine (Fisons Pharmaceuticals, Loughborough, Leics, $\mathrm{UK})$, or $2 \mathrm{mg} / \mathrm{kg}$ protamine. The dose of protamine is that routinely used for human surgical procedures and which neutralizes the anticoagulant activity of heparin (Williams et al. 1989, Wright et al. 1993, Szalados et al. 1994). Blood sampling and plasma derivation were identical to that described above.

In a third experiment, groups of four animals received three intravenous injections of $100 \mathrm{IU} / \mathrm{kg}$ heparin or $0.9 \%$ sterile saline at 0,3 and $6 \mathrm{~h}$ relative to the first injection. The treatment groups were (i) saline at 0,3 and $6 \mathrm{~h}$, (ii) heparin at 0 and saline at 3 and $6 \mathrm{~h}$, (iii) heparin at 0 and 3 and saline at $6 \mathrm{~h}$, and (iv) heparin at 0,3 and $6 \mathrm{~h}$. Blood samples relative to each injection were collected at similar time points to that described above.

Size exclusion chromatography was performed on selected samples to provide some preliminary analysis of the composition of the activin and follistatin entities released by heparin. This method was chosen over more sophisticated modes of separation because the primary question was to ascertain if activin and follistatin existed as complexes or in the unbound state. Sephadex G-75 was selected as the matrix to discriminate between the molecular weight sizes of unbound activin and follistatin (25 and $39-45 \mathrm{kDa}$ respectively) and a complex of activin and follistatin $(\sim 100 \mathrm{kDa})$. Columns of Sephadex G-75 (Pharmacia Biotech, Uppsala, Sweden) were prepared with a bed volume of $20 \mathrm{ml}$ as per the manufacturer's instructions. The loading and running buffer was $0 \cdot 01 \mathrm{M}$ phosphate-buffered saline (PBS) containing $0 \cdot 2 \%$ bovine 
Table 1 Parameters of circulating activin A and follistatin concentrations in ewes in response to different heparin doses ( $n=4$ animals per dose). Data are means \pm S.D. or median (range). Area under the curve is the total area of each treatment group (note that the response parameters for the control group are not presented given that the animals received the appropriate volume of non-heparinized saline solution)

Activin

Peak concentration (ng/ml)

Heparin dose

(IU/kg)

25

100

250

\begin{abstract}
$0 \cdot 48 \pm 0 \cdot 21^{\mathrm{a}}$
$0 \cdot 47 \pm 0 \cdot 09^{a}$

$0 \cdot 89 \pm 0 \cdot 23^{b}$
\end{abstract}

$15(5-20)^{\mathrm{a}}$
$40(40-60)^{\mathrm{ab}}$
$120(120-180)^{\mathrm{b}}$

Area under curve (ng/ml.min)

$$
\begin{array}{r}
30 \cdot 6 \pm 12 \cdot 5^{a} \\
48 \cdot 9 \pm 12 \cdot 1^{a} \\
176 \cdot 8 \pm 53 \cdot 2^{b}
\end{array}
$$

\section{Follistatin}

Peak concentration Timing of peak Area under curve (ng/ml) (min)

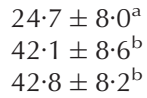

(ng/ml.min)

$$
\begin{aligned}
& 1629 \pm 475^{a} \\
& 3946 \pm 843^{b} \\
& 8912 \pm 2186^{c}
\end{aligned}
$$

Within a column differing superscripts indicate significant $(P<0 \cdot 05)$ differences.

serum albumin (BSA, Sigma, St Louis, MO, USA). Samples were added as $1 \mathrm{ml}$ loading volumes consisting of either $1 \mathrm{ml}$ sheep plasma, human recombinant activin A $(10 \mathrm{ng})$ or purified bovine follistatin $(80 \mathrm{ng})$ diluted in $1 \mathrm{ml}$ loading buffer, or human recombinant activin A (10 ng) or purified bovine follistatin (80 ng) added to $1 \mathrm{ml}$ sheep plasma. Fractions of $0.5 \mathrm{ml}$ were collected off the column and stored at $-20{ }^{\circ} \mathrm{C}$ until assayed. For both activin $\mathrm{A}$ and follistatin, total recoveries from the fractionation studies were close to $100 \%$ for all samples.

Assays

Activin A was measured in an enzyme-linked immunosorbent assay (ELISA) format as previously described (Knight et al. 1996). This assay measures total activin A, that is both free, and due to a dissociation step, follistatinbound activin $\mathrm{A}$. The standard was human recombinant activin A. The mean sensitivity was $0.014 \mathrm{ng} / \mathrm{ml}$, and the mean intra- and interassay coefficients of variation were $5 \cdot 1 \%$ and $5 \cdot 4 \%$ respectively.

Follistatin was measured using a radioimmunoassay (RIA), as previously described (Klein et al. 1991); like the activin A assay it measures both free and bound forms. The polyclonal rabbit antibody employed in the assay (\#202) measures a number of follistatin isoforms likely to be present in both circulatory and tissue-derived samples (Meinhardt et al. 1998). The assay employs purified heterologous bovine follistatin (Robertson et al. 1987) as standard and uses iodinated $35 \mathrm{kDa}$ bovine follistatin as tracer. The assay sensitivity was $2 \cdot 7 \mathrm{ng} / \mathrm{ml}$, the mean $\mathrm{ED}_{50}$ was $13.3 \mathrm{ng} / \mathrm{ml}$, and the intra- and interassay coefficients of variation were $6 \cdot 4 \%$ and $10 \cdot 2 \%$ respectively. Both assays have been validated for and show no non-specific interference when used for heparin-containing samples (Phillips et al. 2000).

\section{Statistics}

Statistical analyses were performed using GraphPad Prism 2.01 Software (GraphPad Software Inc., San Diego, CA,
USA). Activin A and follistatin concentrations were analysed using repeated-measures ANOVA, with Dunnet's post-hoc test where significant differences were detected. Differences in peak concentrations were analysed by one-way ANOVA followed by the Neuman-Keuls posthoc test. Because time to peak concentration was a discrete, non-Gaussian variable, this was analysed by the Kruskall-Wallis test, followed by the Dunns post-hoc test. A significance level of $P<0 \cdot 05$ was used in all analyses.

\section{Results}

\section{Dose-response effects of heparin}

Exogenous heparin over a 16-fold range elicited a rapid release of both activin A and follistatin into the circulation (Table 1). At each of the three doses, proteins were elevated within 5 min of heparin administration, consistent with a rapid release from extracellular sites. However, the response characteristics for each heparin dose differed (Table 1). For activin A, increasing the dose from 25 to $100 \mathrm{IU} / \mathrm{kg}$ had no significant effects, whereas at 250 $\mathrm{IU} / \mathrm{kg}$ there was a significant increase in the peak concentration, time to peak concentration and amount of activin A present in the circulation (area under the curve) compared with the $25 \mathrm{IU} / \mathrm{kg}$ dose. For follistatin, increasing the dose from 25 to $100 \mathrm{IU} / \mathrm{kg}$ affected the peak concentration and amount of follistatin in the circulation. However, no further increase in peak concentration was elicited by $250 \mathrm{IU} / \mathrm{kg}$ heparin, although the amount of follistatin in the circulation was significantly increased compared with either the 25 or $100 \mathrm{IU} / \mathrm{kg}$ dose. Animals which received saline only showed no detectable change in activin A or follistatin concentrations over the 6-h sampling period.

\section{Neutralization of heparin with protamine}

To determine if the release of activin and follistatin by heparin could be blocked by administration of protamine, 
(a)

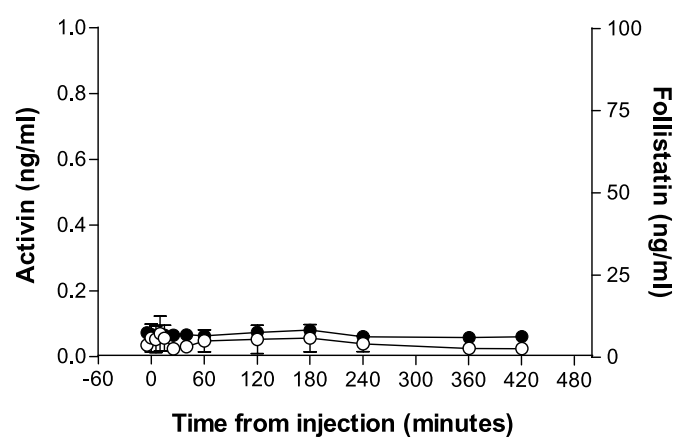

(c)

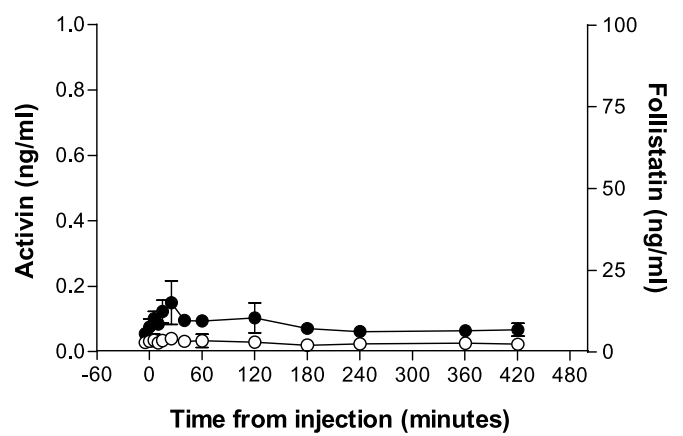

(b)

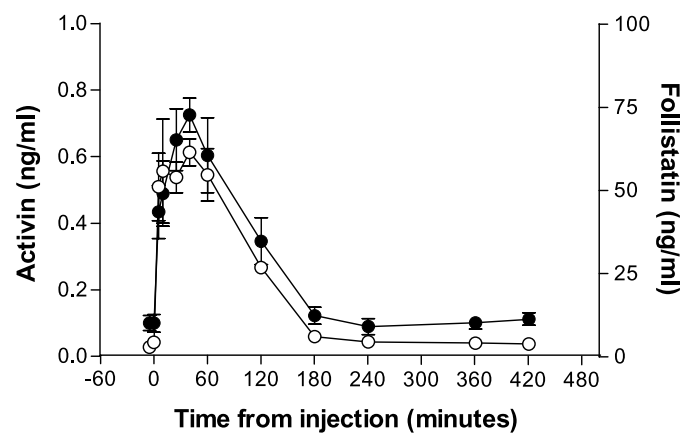

(d)

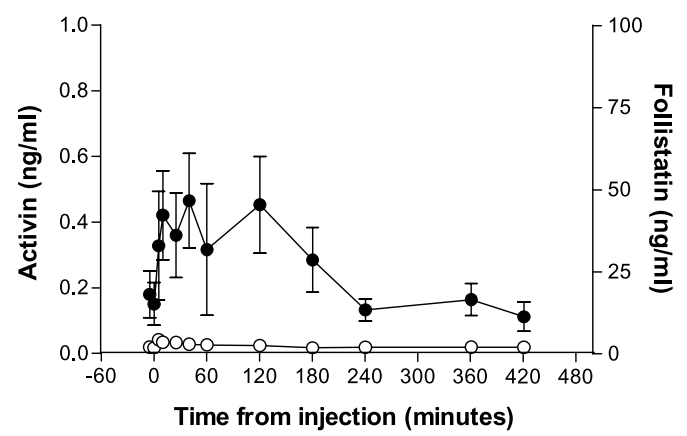

Figure 1 Changes in the plasma concentrations of follistatin (closed circles) and activin A (open circles) following an injection of (a) saline only, (b) heparin $(100 \mathrm{lU} / \mathrm{kg})$, (c) premixed heparin and protamine or (d) protamine $(2 \mathrm{mg} / \mathrm{kg})$ in adult Corriedale ewes. All Figures and values are representative of the mean $(n=4$ animals $) \pm$ S.E.M.

the moderate heparin dose (100 IU/kg) was chosen for subsequent experiments. As shown in the first experiment, the control group injected with saline vehicle showed no significant changes in activin A or follistatin (Fig. 1a), and those animals treated with heparin showed a robust response (Fig. 1b). When heparin was pretreated with $2 \mathrm{mg} / \mathrm{kg}$ protamine before injection, there was no significant change in activin A and follistatin (Fig. 1c), indicating that the protamine was able to ablate the stimulatory effects of heparin. Surprisingly, however, protamine administered in the absence of heparin resulted in a significant increase in follistatin but not activin A concentrations (Fig. 1d). Compared with the group receiving heparin, peak follistatin concentrations for the protamine group were lower $(46 \cdot 2 \pm 14 \cdot 3$ vs $72 \cdot 0 \pm 5 \cdot 1 \mathrm{ng} / \mathrm{ml}$, mean \pm S.E.M.) and took longer to reach peak concentrations (30 min (15-20) vs $20 \mathrm{~min}$ (20-40), median (range)), but follistatin remained elevated above pretreat- ment concentrations for longer (270 $\mathrm{min}(240-300)$ vs 180 min (120-240, median (range)).

\section{Effect of repeated doses of heparin}

To determine the response characteristics to repeated doses of heparin, animals were given either no, one, two or three injections of $100 \mathrm{IU} / \mathrm{kg}$ heparin at three-hourly intervals. As observed for the first experiment, a single injection of heparin elicited a rapid activin A and follistatin response in the circulation, followed by a less rapid clearance over $2 \mathrm{~h}$ (Fig. 2b). Subsequent challenges to heparin $3 \mathrm{~h}$ (Fig. 2c) and $6 \mathrm{~h}$ (Fig. 2d) later resulted in additional rapid responses. Despite a return towards basal levels of activin and follistatin, peak concentrations were increased following subsequent heparin challenges, although these peak concentrations were influenced by an increase in basal levels at the time of the subsequent 
(a)

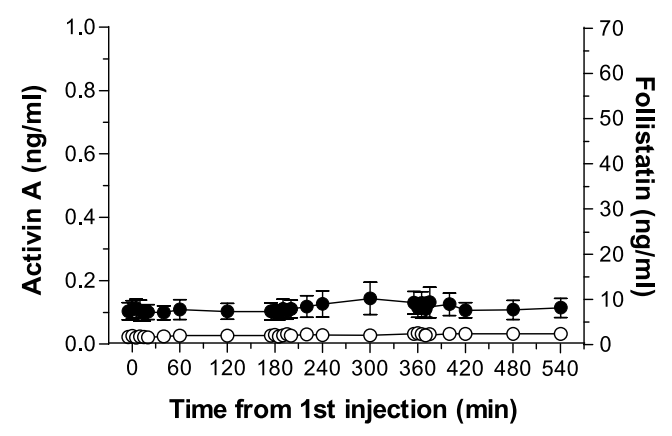

(c)

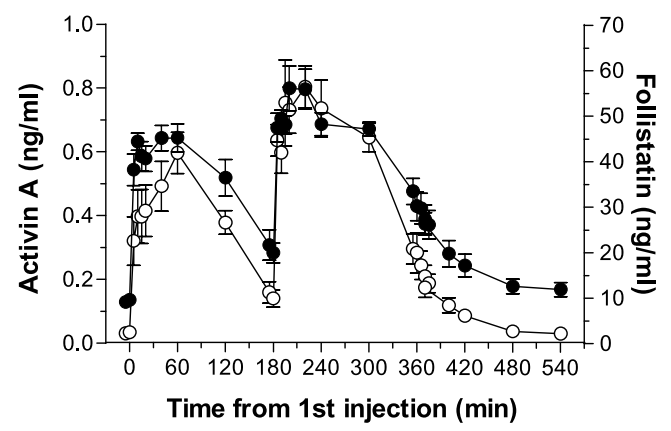

(b)

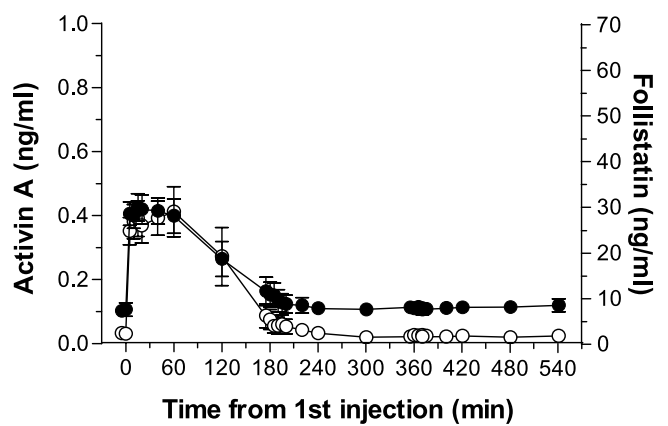

(d)

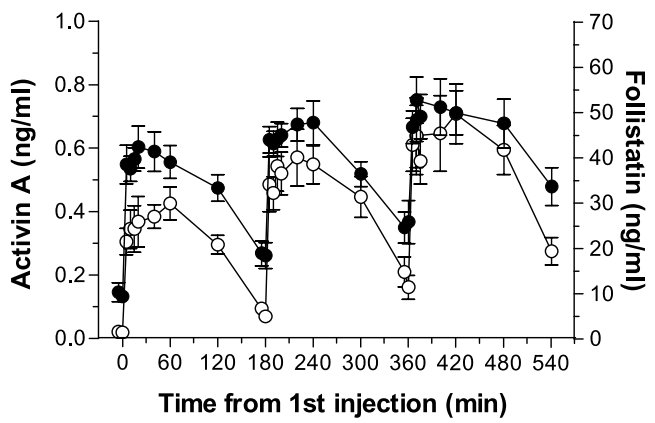

Figure 2 Changes in the plasma concentrations of activin A (open circles) and follistatin (closed circles) following repeated injections of heparin or saline at 0,180 and 360 min relative to the first injection. (a) No heparin injections, (b) heparin $(100 \mathrm{IU} / \mathrm{kg})$ at $0 \mathrm{~min}$, (c) heparin at 0 and $180 \mathrm{~min}$, and (d) heparin at 0,180 and $360 \mathrm{~min}$ in adult Corriedale ewes. All Figures and values are representative of the mean $(n=4$ animals $) \pm$ S.E.M.

challenge. For animals which had received three heparin challenges (Fig. 2d), activin A and follistatin concentrations $3 \mathrm{~h}$ after the third injection remained at peak levels. This suggested that the clearance mechanisms for heparin had become saturated.

\section{Composition of activin and follistatin released by heparin}

Activin A present in plasma from heparin-treated ewes ran at an apparent higher molecular weight following size exclusion chromatography than human recombinant activin A $(25 \mathrm{kDa})$ in PBS, suggesting it was predominantly bound to follistatin (Fig. 3a). When plasma was spiked with $10 \mathrm{ng}$ activin $\mathrm{A}$, the majority of activin A detected in fractions coincided with the position of unspiked plasma. However, a component (approximately $15 \%$ ) eluted in fractions 20-35, coinciding with the elution profile of human recombinant activin A in PBS but not directly replicating the profile.

In another separate series of fractionation studies, the elution characteristics of follistatin from various samples were investigated. The peak of follistatin activity in samples from heparin-treated animals eluted over fractions 6 to 14 , as compared with follistatin activity in fractions from follistatin in PBS which eluted later, in fractions 9 to 16 (Fig. 3b). Conversely, when samples from a ewe treated with protamine were examined, the follistatin peak was at fractions 8 to 15 , later than in those given heparin treatment. Furthermore, when plasma either low (normal) or high (LPS-treated ewes, Jones et al. 2000) in activin A was spiked with $60 \mathrm{ng}$ follistatin, the follistatin peak eluted over a broader range (fractions 7 to 16), covering the elution range of both activin-follistatin complexes and free follistatin, as observed in the plasma from ewes treated with heparin and protamine respectively. 
(a)

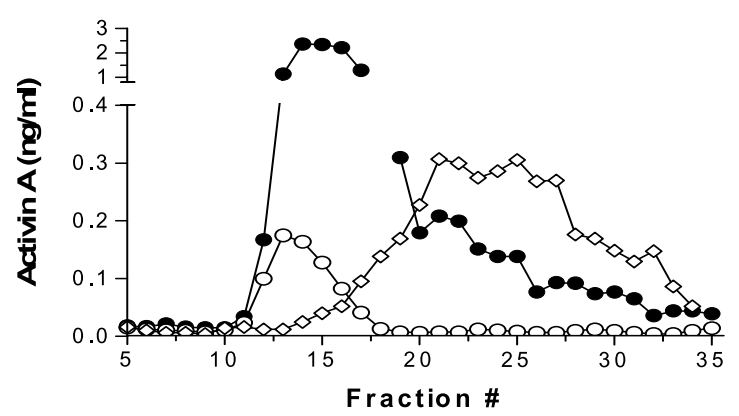

(b)

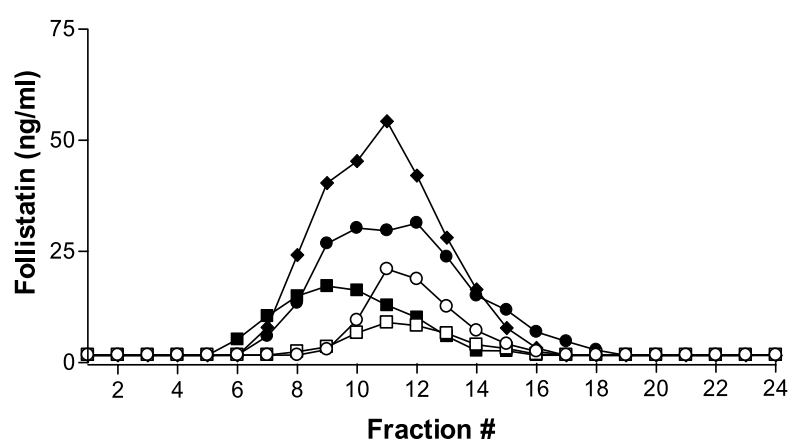

Figure 3 Size exclusion chromatography of activin A and follistatin in selected samples of ewe plasma. (a) Activin A concentrations in the fractions from heparin-treated ewe plasma (open circles), plasma spiked with human recombinant activin A (closed circles) and human recombinant activin A in PBS (open diamonds). (b) Follistatin concentrations in the fractions of purified follistatin in PBS (open circles), follistatin in plasma from protamine-treated ewes (open squares), follistatin in plasma from heparin-treated ewes (closed squares) and follistatin detected in plasma from normal (closed circles) and LPS-treated (closed diamonds) ewes spiked with purified bovine follistatin.

\section{Discussion}

This study supports and extends previous findings that activin $\mathrm{A}$ and follistatin are released into the circulation by interactions with heparin. It has further defined the response by demonstrating a number of parameters - that it is dose-dependent and saturable; that it can be ablated by cotreatment with protamine; that, intriguingly, protamine itself can initiate release of follistatin but not activin A; that repeat responses to heparin can be achieved; and that the majority of activin A and follistatin in the circulation following heparin administration occurs as a complex.

Soluble heparin and its analogues can bind and displace factors such as follistatin from HSPG on cell surfaces and in the extracellular matrix. As activin A itself does not exhibit any affinity for HSPG (Yamane et al. 1998) and the release of activin A by exogenous heparin is concurrent with that of follistatin, this suggests that a significant reservoir of activin-follistatin-288 complexes exist on extracellular matrices. This is consistent with the observations that follistatin is associated with cell surfaces and that activin bound to follistatin accelerates the internalization and lysosomal degradation of activin-follistatin complexes (Inouye et al. 1992, Hashimoto et al. 1997). The rapidity of the release, within $5 \mathrm{~min}$, would infer that it occurs from the luminal surface of the vascular endothelium directly into the circulation. This is supported by the fact that the cell type that the majority of injected heparin reaches is the vascular endothelial cell (Hiebert \& Jaques 1976, Gensini et al. 1984). It therefore seems reasonable that the rapid release of activin A and follistatin is a result of extracellular interaction of heparin with surface bound activin $\mathrm{A}$ and follistatin in the vascular endothelium. The source of this activin A and follistatin on the cell surface of vascular endothelial cells can arise from de novo synthesis of both follistatin and activin by vascular endothelial cell synthesis and secretion (McCarthy \& Bicknell 1993, Michel et al. 1996, Brauman et al. 2000). Alternatively, it could result from the 'trapping' of circulating activinfollistatin that are secreted from many cellular sources (DePaolo 1997, Welt et al. 2002).

Further evidence that the activin and follistatin released by heparin were predominantly released as a complex was provided by size exclusion chromatography. Activin and follistatin present in plasma from heparin-treated ewes eluted as species that were larger than free activin or follistatin (presumably free) released by protamine. This is consistent with findings using a follistatin assay that detects the unbound component, which showed that the concentrations of 'free' follistatin in the circulation are very low (McConnell et al. 1998). However, this assay has not been used to assess the free versus bound components following heparin administration. Of interest was that there was no absolute consistency between activin A and follistatin when response parameters were examined with differing doses of heparin (Table 1). A possible explanation is that different populations of these proteins are released by heparin, most likely a predominant component of follistatin that is bound to activin, and a smaller proportion of 'free' follistatin.

The effect of heparin on activin and follistatin release could be neutralized by pre-incubating heparin with protamine. This presumably resulted from a direct interaction of the opposing charges of protamine and heparin preventing the dissociation of activin-follistatin complexes. However, protamine itself could release follistatin but not activin. The dissociation of follistatin by protamine from HSPG may indicate that the affinity follistatin has for HSPG ( $K_{\mathrm{d}}$ of $5 \mathrm{nM}$, Sugino et al. 1997) is not as high as that of protamine for these moieties. Previous studies have documented similar effects with heparin-binding enzymes 
such as extracellular superoxide dismutase (Karlsson \& Marklund 1988) and lipoprotein and hepatic lipases (Hultin et al. 1994). Alternatively, protamine's strong positive charge may repel follistatin-288 directly from HSPG due to an ionic interaction between protamine and the stretch of positively charged basic amino acids in follistatin-288 (Inouye et al. 1992). Yamane and colleagues (1998) demonstrated that follistatin complexed to activin had an increased affinity for HSPG, suggesting that protamine may only disassociate follistatin-288 which is not complexed to activin, due to its lesser affinity for HSPG.

The results of multiple exposure to heparin suggested that activin-follistatin complexes could be repeatably released from extracellular binding sites. The inference is that membrane-bound follistatin is stable for some hours before internalization and degradation, consistent with in vitro studies showing that significant amounts of degradation products only appear in the medium after $12 \mathrm{~h}$ (Hashimoto et al. 1997). The increase in peak levels of activin and follistatin with repeated heparin challenge and the prolongation of peak levels suggests that the clearance of heparin became saturated. Unfractionated heparin is cleared through two components: a rapid saturable phase reflecting binding to the endothelium, and a slower nonsaturable phase associated with renal clearance (de Swart et al. 1982, Boneu et al. 1987, 1988, Young et al. 1999). These kinetics lend further support to the notion that the vascular endothelium is the primary source of activin and follistatin after heparin release.

The increase in follistatin and activin A following an injection of heparin could have implications for patients receiving heparin during surgery. Activin A and follistatin are potent multifunctional proteins in the context of cardiovascular function, with the recent finding that activin A overexpression maintains vascular smooth muscle cells in a contractile phenotype and inhibits neointimal formation (Engelse et al. 2002). A limitation with using assays that measure total activin A and follistatin for the current studies is that there is no distinction between 'free' and bound follistatin and activin A. Furthermore, currently an appropriate bioassay for plasma or serum activin A or follistatin does not exist. While the majority of activin A and follistatin released appeared to be complexed, as determined by chromatography, it cannot be ruled out that under some circumstances activin A and follistatin dissociate. The affinity of the activin-follistatin complex is very high (46.5 $\pm 0.37 \mathrm{pM}$, Hashimoto et al. 2000), but previously it has been shown that following heparin administration to patients, the disappearance time for activin $\mathrm{A}$ is significantly faster than for follistatin (Phillips et al. 2000). Furthermore, analysis of several parameters from the dose-response studies (Table 1) showed that the upswing of activin and follistatin profiles were concordant, but the disappearance kinetics of activin and follistatin did differ slightly, suggesting that there are subtle differences in the dissociation and association processes for each protein. The significance of these findings remains elusive and we are exploring in continuing studies whether activin A and follistatin released by heparin disappear from the circulation via multiple and possibly divergent pathways.

\section{Acknowledgements}

We thank Bruce Doughton, Karen Perkins, Anne O'Connor, Sue Hayward and Lynda Foulds for excellent technical assistance.

\section{Funding}

This work was funded by the NHMRC of Australia (Program Grant 143786).

\section{References}

Bobik A \& Campbell JH 1993 Vascular derived growth factors: cell biology, pathophysiology, and pharmacology. Pharmacological Reviews 45 1-42.

Boneu B, Caranobe C, Gabaig AM, Dupouy D, Sie P, Buchanan MR \& Hirsh J 1987 Evidence for a saturable mechanism of disappearance of standard heparin in rabbits. Thrombosis Research $\mathbf{4 6}$ 835-844.

Boneu B, Caranobe C, Cadroy Y, Dol F, Gabaig AM, Dupouy D \& Sie P 1988 Pharmacokinetic studies of standard unfractionated heparin, and low molecular weight heparins in the rabbit. Seminars in Thrombosis and Hemostasis $\mathbf{1 4}$ 18-27.

Brauman JN, Smith AI, Scheerlinck JP, de Kretser DM \& Phillips DJ 2000 Activin A and follistatin responses to inflammatory mediators in the endothelium. Proceedings of the 11th International Congress of Endocrinology, Sydney, Australia, Abstract P512.

DePaolo LV 1997 Inhibins, activins, and follistatins: the saga continues. Experimental Biology and Medicine 214 328-339.

Engelse MA, Lardenoye JHP, Neele JM, Grimbergen JM, de Vries MR, Lamfers MLM, Pannekoek H, Quax PHA \& De Vries CJM 2002 Adenoviral activin A expression prevents intimal hyperplasia in human and murine blood vessels by maintaining the contractile smooth muscle cell phenotype. Circulation Research 90 1128-1134.

Esch FS, Shimasaki S, Mercado M, Cooksey K, Ling N, Ying S, Ueno N \& Guillemin R 1987 Structural characterization of follistatin: a novel follicle-stimulating hormone release-inhibiting polypeptide from the gonad. Molecular Endocrinology 1 849-855.

Gensini GF, Fortini A, Lombardi A, Pesciullesi E, Pieroni C \& Neri Serneri GG 1984 Binding of low-molecular-weight heparin to aortic endothelium in rabbits. Haemostasis 14 466-472.

Hashimoto O, Nakamura T, Shoji H, Shimasaki S, Hayashi Y \& Sugino H 1997 A novel role of follistatin, an activin-binding protein, in the inhibition of activin action in rat pituitary cells. Endocytotic degradation of activin and its acceleration by follistatin associated with cell-surface heparan sulfate. Journal of Biological Chemistry 272 13835-13842.

Hashimoto O, Kawasaki N, Tsuchida K, Shimasaki S, Hayakawa T \& Sugino H 2000 Difference between follistatin isoforms in the inhibition of activin signalling. Activin neutralizing activity of follistatin isoforms is dependent on their affinity for activin. Cellular Signalling 12 565-571.

Hiebert LM \& Jaques LB 1976 The observation of heparin on endothelium after injection. Thrombosis Research 8 195-204. 
Hübner G, Hu Q, Smola H \& Werner S 1996 Strong induction of activin expression after injury suggests an important role of activin in wound repair. Developmental Biology 173 490-498.

Hultin M, Olivecrona G \& Olivecrona T 1994 Effect of protamine on lipoprotein lipase and hepatic lipase in rats. Biochemical Journal 304 959-966.

Inouye S, Ling N \& Shimasaki S 1992 Localization of the heparin binding site of follistatin. Molecular and Cellular Endocrinology 90 1-6.

Jones KL, Brauman JN, Groome NP, de Kretser DM \& Phillips DJ 2000 Activin A release into the circulation is an early event in systemic inflammation and precedes the release of follistatin. Endocrinology 141 1905-1908.

Karlsson K \& Marklund SL 1988 Heparin-, dextran sulfate- and protamine-induced release of extracellular-superoxide dismutase to plasma in pigs. Biochimica et Biophysica Acta 967 110-114.

Klein R, Robertson DM, Shukovski L, Findlay JK \& de Kretser DM 1991 The radioimmunoassay of follicle-stimulating hormone (FSH)-suppressing protein (FSP): stimulation of bovine granulosa cell FSP secretion by FSH. Endocrinology 128 1048-1056.

Klein R, Robertson DM \& Clarke IJ 1996 Studies in sheep examining plasma follistatin elevations due to frequent blood sampling or surgery. Reproduction, Fertility and Development $\mathbf{8}$ 273-277.

Knight PG, Muttukrishna S \& Groome NP 1996 Development and application of a two-site enzyme immunoassay for the determination of 'total' activin-A concentrations in serum and follicular fluid. Journal of Endocrinology 148 267-279.

Ling N, Ying S-Y, Ueno N, Shimasaki S, Esch F, Hotta M \& Guillemin R 1986a A homodimer of the $\beta$-subunits of inhibin A stimulates the secretion of pituitary follicle stimulating hormone. Biochemical and Biophysical Research Communications 138 1129-1137.

Ling N, Ying S-Y, Ueno N, Shimasaki S, Esch F, Hotta M \& Guillemin R $1986 b$ Pituitary FSH is released by a heterodimer of the $\beta$-subunits from the two forms of inhibin. Nature 321 779-782.

McCarthy SA \& Bicknell R 1993 Inhibition of vascular endothelial cell growth by activin-A. Journal of Biological Chemistry 268 23066-23071.

McConnell DS, Wang Q, Sluss PM, Bolf N, Khoury RH, Schneyer AL, Midgley AR Jr, Reame NE, Crowley WF Jr \& Padmanabhan V 1998 A two-site chemiluminescent assay for activin-free follistatin reveals that most follistatin circulating in men and normal cycling women is in an activin-bound state. Journal of Clinical Endocrinology and Metabolism 83 851-858.

Mather JP, Moore A \& Li R-H 1997 Activins, inhibins, and follistatins: further thoughts on a growing family of regulators. Experimental Biology and Medicine 215 209-222.

Meinhardt A, O’Bryan MK, McFarlane JR, Loveland KL, Mallidis C, Foulds LM, Phillips DJ \& de Kretser DM 1998 Localization of follistatin in the rat testis. Journal of Reproduction and Fertility 112 233-241.

Michel U, Schneider O, Kirchhof C, Meisel S, Smirnov A, Wiltfang J \& Rieckmann P 1996 Production of follistatin in porcine endothelial cells: differential regulation by bacterial compounds and the synthetic glucocorticoid RU 28362. Endocrinology 137 4925-4934.

Nakamura T, Takio K, Eto Y, Shibai H, Titani K \& Sugino H 1990 Activin-binding protein from rat ovary is follistatin. Science $\mathbf{2 4 7}$ 836-838.

Phillips DJ, Jones KL, McGaw DJ, Groome NP, Smolich JJ, Pärsson $\mathrm{H} \&$ de Kretser DM 2000 Release of activin and follistatin during cardiovascular procedures is largely due to heparin administration. Journal of Clinical Endocrinology and Metabolism 85 2411-2415.

Phillips DJ, Jones KL, Scheerlinck J-PY, Hedger MP \& de Kretser DM 2001 Evidence for activin A and follistatin involvement in the systemic inflammatory response. Molecular and Cellular Endocrinology $180155-162$.

Robertson DM, Klein R, de Vos FL, McLachlan RI, Wettenhall REH, Hearn MTW, Burger HG \& de Kretser DM 1987 The isolation of polypeptides with FSH suppressing activity from bovine follicular fluid which are structurally different to inhibin. Biochemical and Biophysical Research Communications 149 744-749.

Sugino K, Kurosawa N, Nakamura T, Takio K, Shimasaki S, Ling N, Titani K \& Sugino H 1993 Molecular heterogeneity of follistatin, an activin-binding protein. Higher affinity of the carboxyl-terminal truncated forms for heparan sulfate proteoglycans on the ovarian granulosa cell. Journal of Biological Chemistry 268 15579-15587.

Sugino H, Sugino K, Hashimoto O, Shoji H \& Nakamura T 1997 Follistatin and its role as an activin-binding protein. Journal of Medical Investigation 44 1-14.

Sumitomo S, Inouye S, Liu X-J, Ling N \& Shimasaki S 1995 The heparin binding site of follistatin is involved in its interaction with activin. Biochemical and Biophysical Research Communications 208 1-9.

de Swart CA, Nijmeyer B, Roelofs JMM \& Sixma JJ 1982 Kinetics of intravenously administered heparin in normal humans. Blood $\mathbf{6 0}$ 1251-1258.

Szalados JE, Ouriel K \& Shapiro JR 1994 Use of the activated coagulation time and heparin dose-response curve for the determination of protamine dosage in vascular surgery. Journal of Cardiothoracic and Vascular Anesthesia 8 515-518.

Ueno N, Ling N, Ying S-Y, Esch F, Shimasaki S \& Guillemin R 1987 Isolation and partial characterization of follistatin: a single-chain $M_{\mathrm{r}} 35000$ monomeric protein that inhibits the release of follicle-stimulating hormone. PNAS 84 8282-8286.

Vale W, Rivier J, Vaughan J, McClintock R, Corrigan A, Woo W, Karr D \& Spies J 1986 Purification and characterization of an FSH releasing protein from porcine ovarian follicular fluid. Nature 321 776-779.

Welt C, Sidis Y, Keutmann H \& Schneyer A 2002 Activins, inhibins, and follistatins: from endocrinology to signaling. A paradigm for the new millennium. Experimental Biology and Medicine 227 724-752.

Williams NN, Broe PJ, Burke P, Meagher EA, O'Donoghue C, Otridge B \& Bouchier-Hayes D 1989 Heparin kinetics in vascular surgery. European Journal of Vascular Surgery 3 493-496.

Wright SJ, Murray WB, Hampton WA \& Hargovan H 1993 Calculating the protamine-heparin reversal ratio: a pilot study investigating a new method. Journal of Cardiothoracic and Vascular Anesthesia 7 416-421.

Yamane Y, Tohno-oka R, Yamada S, Furuya S, Shiokawa K, Hirabayashi Y, Sugino H \& Sugahara K 1998 Molecular characterization of Xenopus embryo heparan sulfate. Differential structural requirements for the specific binding to basic fibroblast growth factor and follistatin. Journal of Biological Chemistry 273 7375-7381.

Young E, Venner T, Ribau J, Shaughnessy S, Hirsh J \& Podor TJ 1999 The binding of unfractionated heparin and low molecular weight heparin to thrombin-activated human endothelial cells. Thrombosis Research 96 373-381.

Yu J, Shao L-E, Vaughan J, Vale W \& Yu AL 1989 Characterization of the potentiation effect of activin on human erythroid colony formation in vitro. Blood 73 952-960.

Received 8 October 2003

Accepted 6 February 2004

Made available online as an

Accepted Preprint 13 February 2004 